\title{
Pesquisa
}

\section{POLÍTICAS PÚBLICAS E MELHORIA DA QUALIDADE DE VIDA EM SÃO BENTINHO - PB.}

Mário Jorge de Araújo Gonzaga (1)

Gislaine Farias de Oliveira (2)

Hidemburgo Gonçalves Rocha (3)

\begin{abstract}
Resumo
O presente estudo avaliou aspectos dos impactos relacionados das políticas públicas no setor hídrico, à partir da implementação de programas que visaram a ampliação da oferta da água em regiões carentes de recursos hídricos. Observou-se mudanças sociais e espaciais no Município de São Bentinho na Paraíba, bem como as melhorias trazidas por essa modalidade de políticas públicas, em que se destaca a atual gestão territorial e uso potencial dos recursos hídricos na Paraíba. Procurou-se construir uma base de dados sobre a oferta e a demanda de serviços públicos prestados no Município, considerando o acesso à água. Foram discutidas políticas para as mudanças que vem ocorrendo em conseqüência da nova postura dos governantes, em relação ao setor hídrico. Não só nos discurso das elites políticas locais e regionais, como nas suas práticas. No que se refere aos dispositivos metodológicos, elaborou-se uma análise dos dados em campo e, de laboratório, através da qual construímos uma base de dados reveladora das conquistas sociais da população local. Em síntese, os resultados apontaram para uma melhoria dos indicadores de qualidade de vida da população local e do acesso desta à cidadania.
\end{abstract}

Palavras-chave: Cidadania, Recursos hídricos, Qualidade de vida

\section{Introdução}

A problemática da água em consequiência das secas é muito polemizada neste início de século, sendo uma temática que toma novos sentidos na medida em que se consubstanciam novos 
discursos e novas Tecnologias nas práticas políticas. Esse estudo permitirá verificarmos a consubstanciação de um novo discurso a partir dos debates globais sobre os usos dos recursos hídricos em que foram agregados modelos inovadores de gestão política. Desse modo, insere-se no plano retórico político a distribuição de água através de ações voltadas à construção de adutoras, canais e perenização de rios.

Pensamos, a partir do que foi dito acima, duas perspectivas sobre água no semi-árido paraibano. De um lado, há abundância e de outro há escassez. Sobre abundância, Furtado diz que “(...) a água que chega ao mar é muita, e há muita água subtilizada”. (FURTADO, 1998, p.43). Entretanto, como é do conhecimento de todos, o Nordeste brasileiro, e sobretudo a porção semiárida dessa região é tida como associada a área de escassez de água. Realmente, há regiões concentradoras de água no semi-árido, enquanto outras sofrem a sua ausência, principalmente, em áreas de população mais pobre. São justamente nas áreas mais pobres do semi-árido em que os efeitos das secas periódicas, mostram-se avassaladores. As políticas públicas comuns na região não voltaram-se prioritariamente ao abastecimento das áreas mais afetadas com as secas. Porém, confirmamos que atualmente estão em pleno funcionamento as adutoras que transportam águas de regiões concentradoras para as de carência hídrica.

A pesquisa pode ser justificada pelo fato de que não basta no estudo de recursos hídricos numa região como a nossa, fazer uma simplória relação entre oferta e demanda, mas evidenciar como a oferta e a distribuição equiitativa deste recurso podem potencializar esta região, sobretudo aquela de maior concentração demográfica, a ponto de não sofrer com os efeitos climáticos. Com isso, concordamos com Rebouças que,

(...) a avaliação do problema da água de uma determinada região já não pode se restringir ao simples balanço entre oferta e demanda. Deve abranger também os inter-relacionamentos entre os seus recursos hídricos com as demais peculiaridades geoambientais e sócio-culturais, tendo em vista alcançar e garantir a qualidade de vida da sociedade, a qualidade do desenvolvimento sócio-econômico e a conservação das suas reservas de capital ecológico. (REBOUÇAS, pág.:127, 1992.)

A partir destas situações, o objetivo desse trabalho foi avaliar os impactos das políticas públicas no setor hídrico coma implementação de programas que visam a ampliação da oferta de água nas regiões carentes de recursos hídricos, observando as mudanças sociais e espaciais, onde tivemos como canteiro de estudo o Município de São Bentinho no Estado da Paraíba. A questão central foi pensada também a partir dos seguintes objetivos: caracterizar a atual política de gestão territorial e uso potencial dos recursos hídricos na Paraíba, observando o acesso dessa população à cidadania; demonstrar a mudança na condução das políticas públicas no setor hídrico que propiciam transformações espaciais relevantes; construir uma base de dados sobre a oferta e a demanda de água no município de São Bentinho; analisar o atual sistema adutor quanto a sua eficiência social e econômica na área a ser estudada; apresentar as preocupações da populações da 
população local quanto a Educação Ambiental para os Recursos Hídricos; mapear áreas do município que são contempladas com o sistema adutor, mas que não são atingidas com a oferta de água. Avaliamos que esse último objetivo torna-se desnecessário em nosso trabalho, devido o Sistema Adutor Coremas/Sabugi atender apenas a área urbana.

\section{Material e Método}

A utilização de nossos materiais e métodos foi pensada a partir da real situação das ações governamentais voltadas a distribuição e a produção de água na Paraíba que, como é sabido por todos, são frutos de intensas lutas sociais e políticas. Contudo, nossa referência temporal corresponde aos últimos 09 (nove) anos. Esta escolha deve-se ao fato da emancipação deste Município ter ocorrido no referido período.

Além das questões já citadas, foi de relevância na construção de nossa trilha de métodos e materiais, a instauração da política de gestão territorial dos recursos hídricos nos Estados Brasileiros, tendo como proeminência a execução de grandes projetos hídricos no semi-árido paraibano, como a construção de adutoras e canais, assim como também o prosseguimento dos projetos de açudagem.

Ainda levamos em consideração a as questões ambientais e sua polarização, no plano dos discursos, para uns poucos, sua discussão é inócua, não passa de modismo, contudo para outros, é imprescindível o debate, pois a garantia da sustentabilidade do planeta terra - incluindo os seres vivos - depende também de uma melhor compreensão das intervenções do homem no macros sistema ambiental. Pensada a partir das novas políticas sociais e de acesso a cidadania voltada para a Educação Ambiental.

As análises partiram do processo temporal envolvendo os diferentes momentos e prioridades das políticas hídricas estaduais, que correspondeu: estudos comparativos de informações censitárias coletadas junto ao Instituto Brasileiro de Geografia e Estatística (IBGE); e pesquisa local por meio de coleta de dados junto a população de São Bentinho. Os dados foram colhidos por meio de amostragem de domicílios, corresponderam a 5\% da população total do Município.

A descrição dos dados foi de extrema relevância para a interpretação dos resultados. Por meio destes foi possível comprovar e rejeitar as hipóteses que sustentam esta pesquisa.

Pensamos a descrição de acordo com as seguintes fases: 1) pesquisa de laboratório e de campo; e 2) tabulação e descrição de dados.

A primeira consistiu nos trabalhos de pesquisas em laboratório e campo que por meio de amostragem obtivemos informações quanto aos perfis sócio-econômicos definidos na metodologia desse trabalho. A coleta de dados estabeleceu-se em duas fases: 1) estudo de laboratório: foram 
desenvolvidos estudos censitários, considerando o período de emancipação municipal para efeito comparativo com as informações atuais; 2) estudo de campo: para obtermos informações quantitativas e qualitativas nos órgãos públicos do Governo do Estado da Paraíba: SEMARH/PB e CAGEPA. A coleta de dados foi aplicada também à população, através da aplicação de questionários e entrevistas. A aplicação dos questionários se deu forma aleatória, utilizando-se 30 (trinta) unidades As entrevistas foram realizadas com cidadãos que formam a atual cúpula da administração Municipal de São Bentinho.

$\mathrm{Na}$ segunda, Tabulação e a discrição de dados foram obtidas as informações com a aplicação dos questionários. A tabulação é composta por quadros, gráficos e tabelas em que se encontram os dados coletados.

O desenvolvimento destas fases foi realizado em conformidade com os trabalhos LAKATOS e MARCONI, Metodologia do Trabalho Cientifica e FRANZ V. RUDIO, Introdução ao Projeto de Pesquisa Cientifica. Que contem informações quanto aos procedimentos usados na realização de trabalhos desse caráter cientifico.

\section{Resultados e Discussão}

Os resultados desse estudo apontam para uma mudança significativa das políticas hídricas, pois agora a maior parte das ações volta-se a distribuição de água no Nordeste

Como podemos observar, a qualidade de vida da população local tem melhorado. Isso pode ser confirmado com os dados contidos no quadro I abaixo, que traz informações quanto aos indicadores de qualidade de vida e infra-estrutura residencial dos informantes.

Comprovamos ainda que os citadinos da zona urbana do Município de São Bentinho dispõem dos benefícios necessários para uma vida melhor. Podemos atestar os benefícios para a maioria da população urbana no quadro II, que traz informações sobre os serviços públicos prestados na rua dos informantes.

A conservação do capital ecológico também é considerada relevante nesta pesquisa, pois por meio desta preocupação podemos analisar a construção do Sistema Adutor como uma obra de grande porte, mas que segundo denúncias, não houve o cumprimento dos requisitos necessários à conservação do meio ambiente, uma vez que não prestaram os devidos esclarecimentos à população local sobre os impactos ambientais desta obra. Não houve também a preocupação com programas educativos para a população, pois continuam sendo lançados lixos, animais mortos e produtos de uso agrícola (agrotóxicos) no rio Piancó, segundo informações prestadas pelos Secretários de Agricultura, Saúde, Educação e Prefeito. A Educação Ambiental não recebeu a 
atenção necessária que merece um projeto dessa magnitude, como pode ser comprovado no gráfico I, que traz informações quanto ao conhecimento da população local sobre a importância da Educação Ambiental para a preservação do capital ecológico e para a infra-estrutura do Sistema Adutor.

$\mathrm{Na}$ cidade ainda existem esgotos a céu aberto, o que nos faz ver que o sistema de esgotamento sanitário não se dinamizou da mesma forma que o sistema distribuição de água. A distribuição cobre mais de $90 \%$ da população urbana (ver quadro III) e a pavimentação atende a mais de $90 \%$ da área urbana. Segundo informações cedidas pela Prefeitura faltam apenas 3 ou 4 ruas a serem pavimentadas.

O assistencialismo é imperativo no novo modelo de políticas hídricas na região semi-árida. Mesmo com a construção de sistemas de adução de água e conseqüente distribuição para a população das áreas urbanas, podemos observar que no Município estudado, a inadimplência no pagamento da taxa de água para a CAGEPA é significativa. Muitos não tendo recursos para prestação de conta dos seus débitos,solicitam ajuda ao poder público municipal. Podemos observar que em São Bentinho há casos em que as populações não pagam em dia suas contas de água (ver quadro IV e Gráfico I que trazem informações sobre o pagamento dessas taxas). O Prefeito Francisco Carreiro afirmou em conversa que quitou alguns débitos de usuários de água da CAGEPA, alegando que se não fizesse isto essas pessoas ficariam sem água para beber.

Em nossos estudos foi possível observar que estão acontecendo algumas mudanças na forma de atuação das elites políticas. Antes estas assaltavam as instituições para angariar os recursos, e hoje suas estratégias voltam-se a captura dos projetos de desenvolvimento local. Percebemos que o programa que envolve a construção de sistema adutor faz parte de uma agenda de projetos que visam o desenvolvimento local. Nesse sentido, as novas estratégias políticas para obtenção de vantagens parte da distribuição de água para a população em geral que está sendo propiciada pelo sistema adutor. Essa prática tem possibilitado conquistas políticas locais e estaduais. Em São Bentinho percebemos permanência das estruturas de poder desde o momento da emancipação do Município.

A população urbana beneficiou-se do Sistema Adutor, pois há a garantia de fornecimento de água durante o ano inteiro, pois o acesso à água em quantidade e qualidade é um direito de todos os cidadãos. Entretanto, há quem usa politicamente os direitos do cidadão para obtenção de vantagens políticas, ou seja, a permanência no poder. A zona rural ainda permanece vivendo na mesma situação de outrora, ou seja, em momentos de seca fica sem abastecimento de água e de alimentos. Isso demonstra não só a mudança do objeto do discurso - passagem da seca à água, mas a permanência de seus objetivos - vantagens políticas e manutenção das estruturas de poder.

O nosso trabalho aponta não só para as políticas voltadas ao represamento de água e das vantagens políticas obtidas, mas nota-se as ações no sentido de dotar as áreas mais carentes de recursos hídricos de uma infra-estrutura espacial que integra regiões carentes com as 
concentradoras desse recurso. Observamos então a busca pela equidade territorial na distribuição de água na região semi-árida. Contudo, as vantagens políticas ainda são notórias.

\section{Apresentação dos Quadros e Gráficos}

\begin{tabular}{|l|l|c|}
\hline \multicolumn{1}{|c|}{ ITENS } & SIM & NÃO \\
\hline TV/CORES & 24 & 6 \\
\hline SOM & 17 & 13 \\
\hline GELADEIRA & 26 & 4 \\
\hline PARABÓLICA & 9 & 21 \\
\hline FERRO ELETRICO & 24 & 6 \\
\hline VENTILADOR & 23 & 7 \\
\hline FOGÃO & 28 & 2 \\
\hline
\end{tabular}

Fonte: Dados obtidos de pesquisa direta, 2007.

Quadro I - Quanto aos Indicadores de Qualidade de Vida dos Informantes Quanto à InfraEstrutura Residencial

Sobre os indicadores de qualidade de vida dos informantes quanto a infra-estrutura residencial, consideramos os seguintes itens que são seguidos por seus respectivos valores: TV/cores, $80 \%$ dos informantes dispõe de tal bem e $20 \%$ não o possui; som $57 \%$ possui tal bem e $43 \%$ não possui; geladeira $87 \%$ dos informantes o disponibilizam e $14 \%$ dos informantes não o possui; parabólica $30 \%$ de todos os informantes conta com tal bem e $70 \%$ não possui; ferro elétrico $80 \%$ possui e $20 \%$ não disponibiliza; ventilador $77 \%$ possui e $23 \%$ não conta com os benefícios do referido bem; fogão $93 \%$ dos informantes possui enquanto $7 \%$ não conta com tal bem em suas residências.

A seguir, apresenta-se o quadro II . Esse quadro trata dos indicadores dos serviços públicos prestados na rua dos informantes. Sendo os seguintes: CAGEPA, 97\% dos informantes disponibilizam em sua rua dos serviços oferecidos pela estatal. Podemos observar que quase $100 \%$ do total dos informantes contam com água em suas residências; SAELPA, presta serviço a 100\% dos informantes; TELEMAR, com prestação de serviços a 73\% dos informantes; Agentes de Saúde, com atendimento a $93 \%$ dos informantes. 


\begin{tabular}{|c|c|c|c|c|}
\hline \multirow{2}{*}{ TIPO DE SERVIÇO } & \multicolumn{2}{|c|}{ OPÇÃO } & \multirow{2}{*}{$\begin{array}{c}\mathrm{N}^{\circ} \mathrm{DE} \\
\text { INFORMANTES }\end{array}$} & \\
\hline & SIM & NÃO & & \\
\hline CAGEPA & 29 & 1 & 30 & 7 \\
\hline SAELPA & 30 & $\mathbf{0}$ & 30 & 00 \\
\hline TELEMAR & 22 & 8 & 30 & 6 \\
\hline AGENTES DE SAÚDE & 28 & 2 & 30 & 4 \\
\hline PAVIMENTAÇÃO & 26 & 4 & 30 & 8 \\
\hline OUTROS & $\mathbf{0}$ & 30 & 30 & 00 \\
\hline
\end{tabular}

Fonte: Dados obtidos de pesquisa direta, 2007.

Quadro II - Indicadores dos Serviços Públicos Prestados na Rua dos Informantes

\begin{tabular}{|c|l|c|}
\hline RENDA FAMILIAR & $\mathbf{N}^{\mathbf{0}}$ & $\%$ \\
\hline Menos de um salário mínimo & 1 & 37 \\
\hline $\begin{array}{l}\text { Igual ou mais de um salário } \\
\text { mínimo }\end{array}$ & 9 & 53 \\
\hline
\end{tabular}

Fonte: Dados obtidos de pesquisa direta, 2007.

Quadro III - Indicadores de Renda Familiar

\begin{tabular}{|l|l|}
\hline \multicolumn{1}{|c|}{ TIPO } & \multicolumn{1}{c|}{$\mathbf{N}^{\mathbf{0}}$} \\
\hline ENCANADA & 28 \\
\hline POÇO & 2 \\
\hline CHAFARIZ & \\
\hline AÇÚDE & \\
\hline & \\
CISTERNA DE PLACAS & \\
\hline
\end{tabular}

Fonte: Dados obtidos de pesquisa direta, 2007.

Quadro IV - Modalidade De Acesso À Água Na Área Urbana 


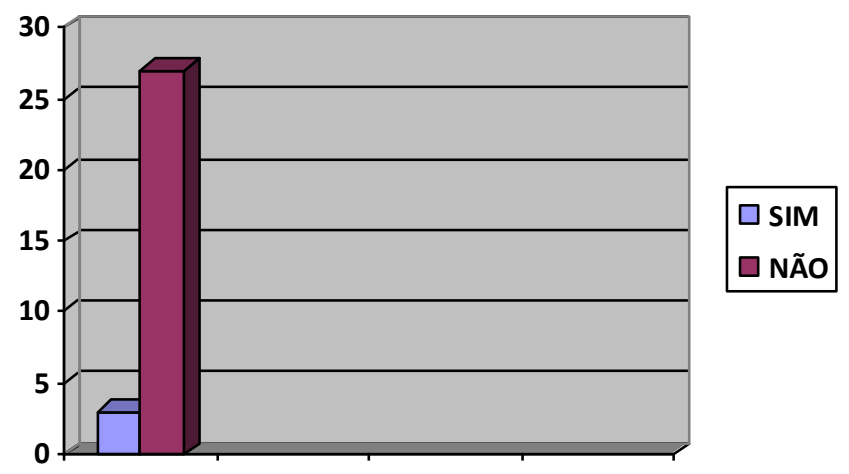

Fonte: Dados obtidos de pesquisa direta, 2007.

\section{Gráfico I - Conhecimento da População sobre a Importância da Educação Ambiental}

O gráfico I mostra que 97\% dos informantes não têm conhecimento da importância da Educação Ambiental para a preservação do capital ecológico e 7\% tem conhecimento da necessidade da preservação ambiental para a vida, contudo esse conhecimento foi adquiro individualmente, sem que nenhuma informação tenha sido passada pelos órgãos competentes pela construção da adutora.

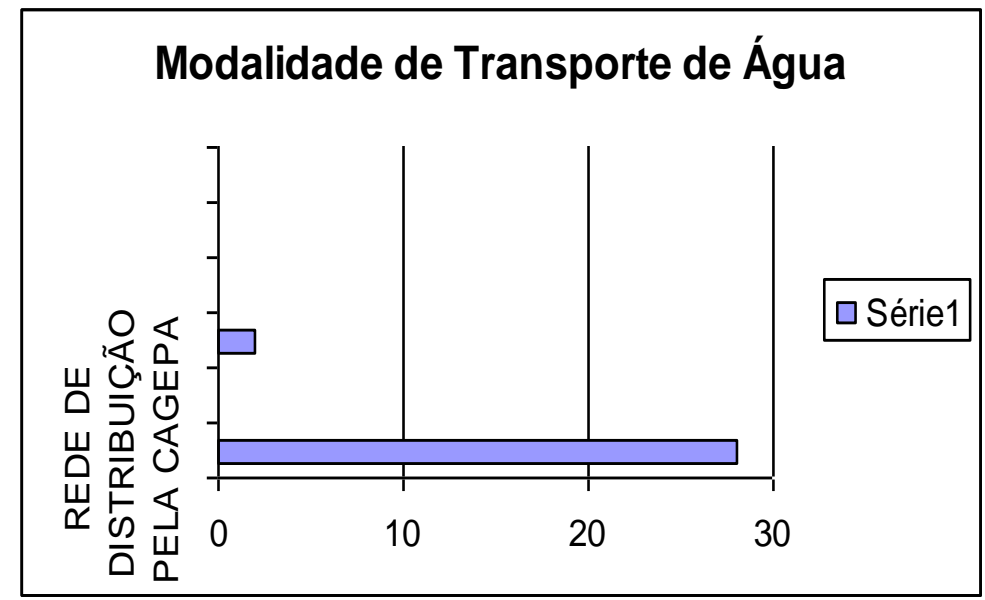

Fonte: Dados obtidos de pesquisa direta, 2007.

Gráfico II - Modalidade de Transporte de Água

O gráfico II acima mostra que $97 \%$ dos informantes tem como modalidade de transporte de água a rede de distribuição fornecida pela CAGEPA e 7\% transportam por outros meios, sobretudo, lombo de animais ou carroça. 


\begin{tabular}{|c|c|l|l|l|l|}
\hline \multicolumn{2}{|c|}{$\begin{array}{c}\text { SOFRE COM A } \\
\text { FALTA DE ÁGUA }\end{array}$} & \multicolumn{2}{c|}{$\begin{array}{c}\text { PAGAMENTO DA } \\
\text { TAXA EM DIAS }\end{array}$} & $\begin{array}{c}\text { EFETUA PAGAMENTO } \\
\text { DE TAXA DE ESG. } \\
\text { SANITÁRIO }\end{array}$ \\
\hline SIM & 2 & SIM & 27 & SIM & - \\
\hline & & & & & \\
NÃO & 28 & NÃO & 3 & NÃO & 30 \\
\hline
\end{tabular}

Fonte: Dados obtidos de pesquisa direta, 2007.

\section{Quadro V - Opinião dos Informantes em Relação à Falta de Água}

$\mathrm{O}$ quadro $\mathrm{V}$ conta com dados sobre a falta de água, indicando que $7 \%$ dos informantes diz sofrer com o problema citado e 93\% dos informantes dizem não haver problema. Buscamos informações sobre o pagamento da taxa de água em dia. Os resultados são os seguintes: $90 \%$ fazem o pagamento em dia para a CAGEPA e $10 \%$ age de forma diferenciada. Quanto ao número de informantes que efetuam o pagamento de taxa de esgotamento sanitário, $100 \%$ declararam não efetuar o pagamento desta taxa.

\section{Conclusões}

Neste trabalho concluímos que o principal impacto ocorrido no Município de São Bentinho foi o crescimento da água canalizada pela CAGEPA no qual chega a atender mais de $90 \%$ da zona urbana(ver quadro IV). Vale ressaltar a falta de conhecimento da população local quanto a importância com a preservação do capital ecológico para a manutenção e bom funcionamento do Sistema Adutor Coremas - Sabugi , como também na vida dos moradores e de suas futuras gerações (ver gráfico I). Outros pontos importantes que foram identificados nesse estudo foi a falta de gerenciamento da água gerando problemas como a própria escassez da mesma.

Em nosso cotidiano e em caráter cientifico surge uma nova discussão sobre os conflitos envolvendo uso múltiplo de águas, que implica na necessidade de rever os valores e a importância da água em nossa vida e no desenvolvimento sóciopolítico e econômico. Por isso é necessário repensarmos sobre como manusear esse recurso tão importante para nossa vida, para que num futuro vindouro o mesmo não se torne escasso para as novas gerações. 


\section{Referencias}

AB'SABER, A. A universidade brasileira na (re) conceituação da educação Ambiental. Educ.Bras.Brasília, 15(31): 59-106, 2º sem. 1996.

CARVALHO, Inaiá Maria Moreira de. O Nordeste e o regime autoritário: discursos e práticas do planejamento regional. São Paulo: Hucitec: Sudene, 1987.

CASTRO, Iná Elias de. Seca versus seca. Novos interesses, novos territórios, novos discursos no Nordeste. In.: CASTRO, Iná E. de, GOMES, Paulo C. da C. \& CORRÊA, Roberto L. (orgs.). Brasil: questões atuais da reorganização do território. - Rio de Janeiro: Bertrand Brasil, 1996.

O mito da necessidade: discurso e prática do regionalismo nordestino. Rio de Janeiro, Bertrand Brasil, 1992. p.235.

FURTADO, Celso. Seca e Poder: entrevista com Celso Furtado / entrevistadores Maria da Conceição Tavares, Manoel Correia de Andrade e Raimundo Pereira - SP: Fundação Perseu Abramo, 1998.

GADOTTI, Moacir. Pedagogia da Terra. 3. ed. São Paulo: Peirópolis, 2000.

GOVERNO DO ESTADO DA PARAÍBA. Lei n 6.308 , de 02 de julho de 1996. Institui a Política Estadual de Recursos Hídricos, suas diretrizes e dá outras providências. Disponível na INTERNET via http://www.al.pb.gov.br. Consulta realizada em 2002.

LAKATOS, E.M. e MARCONI, M. de A. Metodologia do trabalho cientifico: procedimentos básicos, pesquisa bibliográfica, projeto e relatório, publicação e trabalho cientifico. 4.ed. São Paulo: Atlas, 1992.

REBOUÇAS, Aldo C. Água na região Nordeste: desperdício e escassez. Estudos Avançados USP,11 (29), 1997. p.127-154.

TRAJANO, Josefa Lúcia Jordão de Sousa; BARACUHY, Geraldo. Cidadania, Responsabilidade, Meio Ambiente e Recursos Hídricos. ABEAS/UFPB: Brasília, 1999. 


\section{Sobre os Autores:}

1. Mário Jorge de Araújo Gonzaga é Bacharel em Direito pela FAFIC de Cajazeiras, Licenciado em Geografia pela UECE-FAFIDAM. Especialista em Gestão Ambiental pela UFCG, Mestre em Ciências da Educação pela Universidad SanCarlos-PY.

E-mail: mariojorgeadvsth@hotmail.com;

2. Gislaine Farias de Oliveira é Bacharel em Administração de Empresas e Pós-Graduada em Geografia com ênfase nas questões ambientais. E-mail: gisleinefarias44@ hotmail.com;

3. Hidemburgo Gonçalves Rocha é Doutor em Farmacologia e Professor da Universidade Federal do Ceará. E-mail: hidemburgo.rocha@hotmail.com;

\section{Como citar este artigo (Formato ISO):}

GONZAGA, M.J.A.; OLIVEIRA, G.F. ROCHA, H.G. Políticas públicas e melhoria da qualidade de vida em Bentinho-PB. Id on Line Revista de Psicologia, Fevereiro de 2013, vol.1, n.19, p. . 66-76. ISSN: 1981-1189. 